\title{
Harm, care and babies: An inequalities and policy discourse perspective on recent child protection trends in Aotearoa New Zealand
}

Emily Keddell, University of Otago, New Zealand

\begin{abstract}
INTRODUCTION: Examining basic trends in child protection statistics give some insight into the functioning of the system overall.

METHODS: This article uses Official Information Act and publicly available data to examine recent trends of children in contact with the Aotearoa New Zealand child protection system. It discusses these trends with reference to child protection policy reforms, and an inequalities perspective.
\end{abstract}

FINDINGS: There has been an increase of children in care despite steady reductions in hospitalisations for physical abuse and possibly child deaths, accepted reports of concern, abuse substantiations and entries to care. The increase is caused by fewer children exiting care, particularly for children under 10 years old. There is a $33 \%$ increase in babies removed; this is regionalised and with more use of legal orders on unborn, as opposed to older babies. Disproportionality for Māori is increasing, while other groups remain stable or reduce. The use of kinship care has increased.

IMPLICATIONS FOR PRACTICE OR POLICY: Changes in rates of contact with the child protection system reflect complex interactions between demand and supply of services, social inequalities, the policy context and practice logics. Changing decision-making at intake reflects tightening criteria to focus on only the highest risk families. However, "supply" policies that focus on early removal to permanency and early-intervention discourses may result in an increase in younger children entering care, and staying longer once they get there. "Demand" policies affecting preventive service provision, social protections and institutionalised bias may also be contributors. More research is needed to fully understand these patterns.

KEYWORDS: Child protection; Oranga Tamariki; child abuse prevention; inequalities; babies

AOTEAROA NEW ZEALAND SOCIAL WORK 31(4), 18-34.

CORRESPONDENCE TO: Emily Keddell

emily.keddell@otago.ac.nz
Trends in descriptive child protection statistics give some insight into the functioning of the system overall. These trends act as the canaries down the coalmine of changing social contexts, and large changes should alert policy-makers and practitioners to the emerging need for an examination of the interaction between policy, practice and outcomes. Marked changes in system contact can be interpreted using concepts from an inequalities approach to child welfare. An inequalities perspective in child welfare, similarly to health inequalities, considers how children's chances of system contact, their experiences of that contact and the outcomes of it, are patterned by social 
inequalities relating to demographic factors such as age, gender ethnicity, socioeconomic status, location and disability (Bywaters, 2015; Keddell \& Davie, 2018). An inequalities perspective also examines how factors relating to the demand and supply of services interact with demographic factors to influence outcomes, for example, the rising numbers of children in care in England have been linked to public sector austerity cuts that have increased family poverty and reduced the funding of community services (Bywaters et al., 2018a; Hood, Goldacre, Gorin, \& Bywaters, 2019). Demand and supply concepts emphasise that patterns of system contact can be influenced by the quantity of a service offered, its entry and exit criteria, goodness of problem fit, cultural acceptability and its conceptual or discursive basis. This discursive basis, in turn, is sensitive to political, practice and public perceptions, various stakeholders and constructions of the problem (Keddell, 2017a).

In the Aotearoa New Zealand child protection context, an inequalities theoretical framework draws attention to the intersections between population factors such as ethnicity and class (particularly for Māori), and the nature, structure and aims of the child welfare system. This system includes social protections such as income, housing and health services, family support services in the NGO and Iwi sectors, and the statutory child protection service (currently called Oranga Tamariki (OT)). This article draws on publicly available data and statistics obtained under the Official Information Act to describe trends in the population of children in contact with the statutory child protection system, and discusses them with reference to an inequalities theoretical framework and the policy context. The policy context includes the child protection reforms that began in Aotearoa New Zealand in 2015 with the release of the "Modernising Child Protection" report of the expert panel (Ministry of Social Development, 2015). While the ongoing rhetoric of these reforms claims that they will reduce the numbers of children in care, this is not borne out so far by trends of children in care 2015-2018. Instead, against a backdrop of reducing objective measures of physical abuse, children in care overall have increased, with the largest increase showing in the numbers of children in care under the age of 10. A closer examination shows that entries to care have reduced, but there has been a larger reduction in exits from care: despite fewer children entering care, they remain there for longer. While entries of all-age children have decreased, there has been an increase in young children and babies entering care. This is particularly concerning, especially as this increase is driven by an increase in the rate of Māori babies removed within three months of birth. There is more use of legal orders obtained on unborn babies to implement removal, (as opposed to babies from birth to one year old) and more use of legal orders as opposed to "by agreement" to bring babies into care. However, the use of whānau/kinship care is also increasing, suggesting that, while more children are in care, they are more likely to be retained within their wider whānau.

These complex changing patterns have consequences for the manner in which the relationship between the state and families is conceptualised, and for Māori whose disproportionate representation in the child protection system is worsening rather than improving. This article describes these complex patterns and discusses them with reference to dynamics on the supply side of service provision, that is, how the statutory service (Oranga Tamariki) operates, as well as those affecting the demand side: what might influence the need for child protection services in the community? The interface between these two systems is also discussed. Tentative directions are suggested for further research to investigate more fully the emerging areas of concern highlighted by these basic descriptive trends.

\section{Child protection in the risk society: early intervention in the policy reform context}

Child protection systems in many nations are grappling with increasing numbers of children coming into the care system, and the 
reduction of funding of the key preventive conditions, services and provisions that reduce this demand (Bywaters, Scourfield et al., 2018). Fewer preventive resources combined with an emphasis on "child focussed practice", managerialist notions of professional accountability relating to reputational organisational risk, and an expanding lexicon of definitions of child abuse has fed the hungry "risk monster" of the child protection system (Featherstone, Gupta, Morris, \& Warner, 2016). Poverty and its ills are consistently connected to child protection system contact, yet addressing poverty in policy and in social work practice remains scarce (Bywaters et al., 2015; Featherstone et al., 2016; Keddell, Davie, \& Barson, 2019). Instead, concepts relating to risk, accountability and responsibility dominate, in line with the embedded nature of the neoliberal economic system evident in Aotearoa New Zealand since 1984 (Hyslop, 2017). As supports and protections available to families reduce, the risk focus contributes to a more authoritarian child protection system, limiting family participation and increasing intervention. This has been observed in many countries, particularly England, but also here in Aotearoa New Zealand (Hyslop, 2017; Parton, 2016). The NGO and Iwi support services available to families have been routinely underfunded, while child poverty rates remain high (Duncanson et al., 2018; Jenkins, 2019).

Three key policy events have shaped the Aotearoa New Zealand policy landscape since 2012. The Vulnerable Children's reforms, following the green and white papers of the same name, took place between 2012 and 2014 (though some legislative amendments were implemented aftert this time), in 2014 the Office of the Chief Social Worker (within Oranga Tamariki) released their workload report, and in 2015, an extensive "modernisation" reform of the child protection system in Aotearoa New Zealand was announced (Ministry of Social Development, 2012, 2015; Office of the Chief Social Worker, 2014). The workload and casework report highlighted the problem of overworked caseworkers in the context of an immense increase in notifications, and proposed focussing more squarely on high risk cases, setting clearer parameters around "core business" as a way to reduce less serious cases entering the system. The Vulnerable Children's reforms focussed most on surveillance and notification policies, but also promised to get tough on child abuse. This effectively demonised parents in the public narrative, and severed any connection between harm to children and the social context of people's lives, with the Minister declaring poverty was "no excuse for child abuse" (Ministry of Social Development, 2012, p. 4).

Against this background, a panel was appointed to lead the 2015 reforms, led by an economist who had previously led welfare reform, with no experience in child protection. This reform created a new child protection ministry (Oranga Tamariki), and would eventually propose changes to care, practice, and "early intervention" areas. While a set of complex reforms, it focussed on introducing the National-led government's broader social policy of social investment to child protection, where children at risk of future cost to the state could be identified early and intervened upon, as well as a focus on child trauma and responsiveness to children's "voice". The early intervention focus was less developed than the focus on improving services for children already in care, and the staged implementation resulted in the proposed "intensive intervention" and "prevention" services for families before children may need to enter care, coming last in the reform implementation (both are yet to be introduced).

Neither these reforms, nor the previous reform (the Vulnerable Children's reforms), connected structural conditions to system contact, such as poverty or housing. Despite highlighting the disproportionate representation of Māori in the system, there was little analysis as to the causes of this disproportionality either in economic 
or in any other terms. The emphasis on early permanency in safe and loving homes from a policy process with limited inclusion of the views of parents and whānau, and extensive input from young people in permanent care, led to a set of reforms focussed most on children in permanent care. There was much less focus and conceptual understanding of the experiences of the much larger group of families who have system contact but do not have children removed, or the reasons for children entering care (Keddell, 2018).

The reforms led to multiple legislative changes, including amending the Children, Young Persons and their Families Act to become the Oranga Tamariki Act, 1989, and also proposed the Oranga Tamariki Amendment Act, 2017 (Ministry of Social Development, 2015). These amendments introduced new principles that emphasised "children's best interests" as well as the rights of Māori children to retain connections to their whānau, hapū and iwi (after bitterly contested debates over the drafted legislation). In short, the existing tensions in the act between family empowerment and children's best interests were reinscribed, with both family and whānau oriented sections, and those that focus exclusively on the child's rights to protection and best interests. For example, families will be both assisted to, "at the earliest opportunity, to fulfil their responsibility to meet the needs of their children and young persons" (s4 (d)) but also, where children "require care under the Act" will be ensured "a safe, stable, and loving home from the earliest opportunity" (s4 (e) (i).

These two concepts, child protection and family support, as ever, create tensions in the resulting changes between a child focussed orientation emphasising the rights of children as individuals and their developmental outcomes, with a child welfare orientation, supported by Māori concepts and interests, that emphasise children's and parents' rights to retain connections with their families, identities and whakapapa (Gilbert et al., 2011). One amendment from the earlier Vulnerable Children reforms, s18A, created a new way in which children can be removed. If earlier children have been removed with no reasonable hope of return, this creates a "subsequent parent" status. Every parent thus statutorily defined must prove in court that they are safe to parent any subsequent child they may have.

Alongside these system-related factors affecting the supply of child protection services, factors external to the child protection system also affect contact patterns. These include the real predicaments of family life in contexts of high poverty, a housing crisis, precarious employment, discrimination, poor access to adult health services, and the underfunding of services that aim to improve parent-child relationships. In Aotearoa New Zealand, there are high rates of child poverty, stagnant spending on preventive services as mentioned, and family stress created by housing shortages (Jenkins, 2019; Simpson, Duncanson, Oben, Wicken, \& Gallagher, 2016). There is limited access to mental health services in some regions, leading to a national inquiry (New Zealand Government, 2019). Contact with the child protection system is highly stratified by socioeconomic status. Those in the most deprived decile have 9.4 times the chance of children entering care as those in the least deprived decile (Keddell et al., 2019). Many studies show that ethnic discrimination affects Māori access to health care, and perceptions of the relative risk of Māori families (Bécares, Cormack, \& Harris, 2013; Keddell \& Hyslop, 2019).

In this complex policy context, what are the trends in child protection system contact, and what are the tentative links to be made with the policy context? In what follows, I present trends in system contact, and discuss them with reference to this context. 


\section{Methods}

This article draws on several sources of data: the publicly available data provided by Oranga Tamariki and their predecessor on notifications, substantiated findings, family group conferences and children in care up until 2017 (Ministry of Social Development, 2018). Rates from these data were then calculated using the Estimated Resident Population by age, supplied by Statistics New Zealand through their NZ.Stat service (http://nzdotstat.stats.govt.nz/wbos/). As the age of children as defined by the Oranga Tamariki Act was unchanged by 2017, the age range used was $0-16$. Numbers of baby removals within three months of birth were obtained through two Official Information Act requests made by the author in 2015 and 2018 (Oranga Tamariki 2015b, 2018). They were supplied by region and ethnicity. Birth denominators were obtained from Statistics New Zealand through publicly available datasets of live births by year. Entries and exits were also obtained by Official Information Act request (Oranga Tamariki, 2015a). The data on regions and pathways into care for babies removed up to 12 months of age were released by Oranga Tamariki in 2019 (Oranga Tamariki, 2019). Any data not from these sources are noted in the text.

These data have several limitations. Administrative data sourced from the child protection system reflects system contact, not rates of child abuse. Statistics on children in care only reflect those in the custody of the Chief Executive not those children who have been discharged into permanent care arrangements, are in the custody of an NGO, or who are in informal care with grandparents or other whānau members. Care numbers are also "point in time" data, not showing all children in the care system over each year, but on a given day. It may have recording errors relating to ethnicity, depending on who recorded it. Population estimates may be inaccurate as they are based on population projections. The presentation of statistics here are descriptive statistics only, so only broad patterns can be identified.

\section{Key findings}

The key findings describe the patterns of children reported to Oranga Tamariki, and some other measures of child physical abuse. This section then shows the increase of those in care, outlines entries and exits, Māori disproportionality, the increase of kinship care, and several factors relating to babies entering the care system.

\section{Reports of concern and child abuse "substantiations"}

The first observable trend is at the front-end of the system, where families are notified to Oranga Tamariki, then either accepted or rejected as "reports of concern". While reports of concern overall have remained stable, within that count, general care and protection reports have slightly reduced, while police family violence referrals have increased steadily from 57,776 to 77,081 , as can be seen in Figure 1 . As can be seen in Figure 2, despite overall reports of concern remaining stable (at around 150,000), there has been a decrease in substantiated child abuse between 2013 and 2017, caused primarily by a large reduction in emotional abuse and neglect substantiations. The rates of emotional abuse have nearly halved, for example, from 11,386 in 2013, to 6,737 in 2017, and neglect from 4,957 to 3,226 . Sexual abuse has dropped slightly, but physical abuse remains very stable.

One explanation for the reducing care and protection reports of concern is that those notifications accepted as reports of concern have to meet a higher threshold for acceptance by OT, or that certain types of cases are no longer accepted (Office of the Chief Social Worker, 2014). In a similar manner, the sharp reductions in substantiations without equal reductions in notifications suggest that the cause is changes in the application of decisionmaking tools or logics at intake, rather than true changes in the incidence of these types of child abuse. 

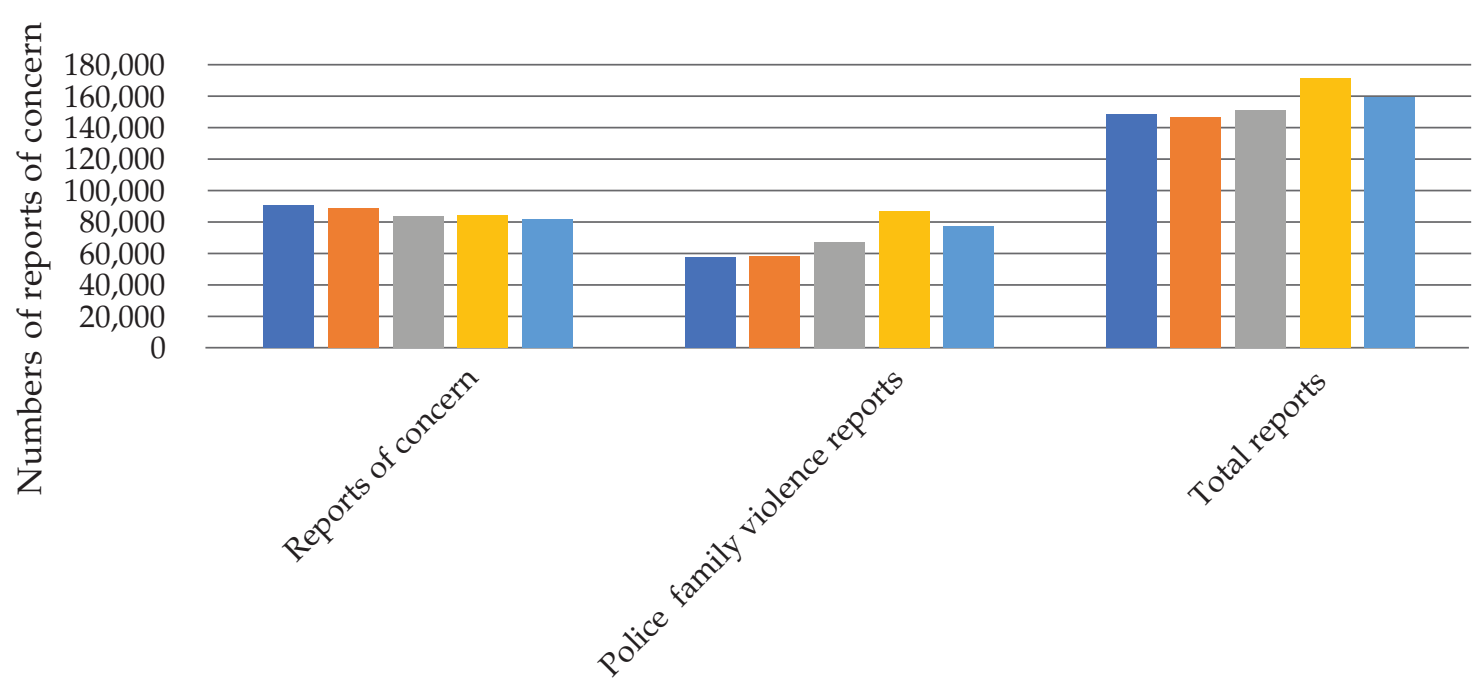

Reports of concern type and years

Figure 1. Reports of concern to Oranga Tamariki 2013-2017.

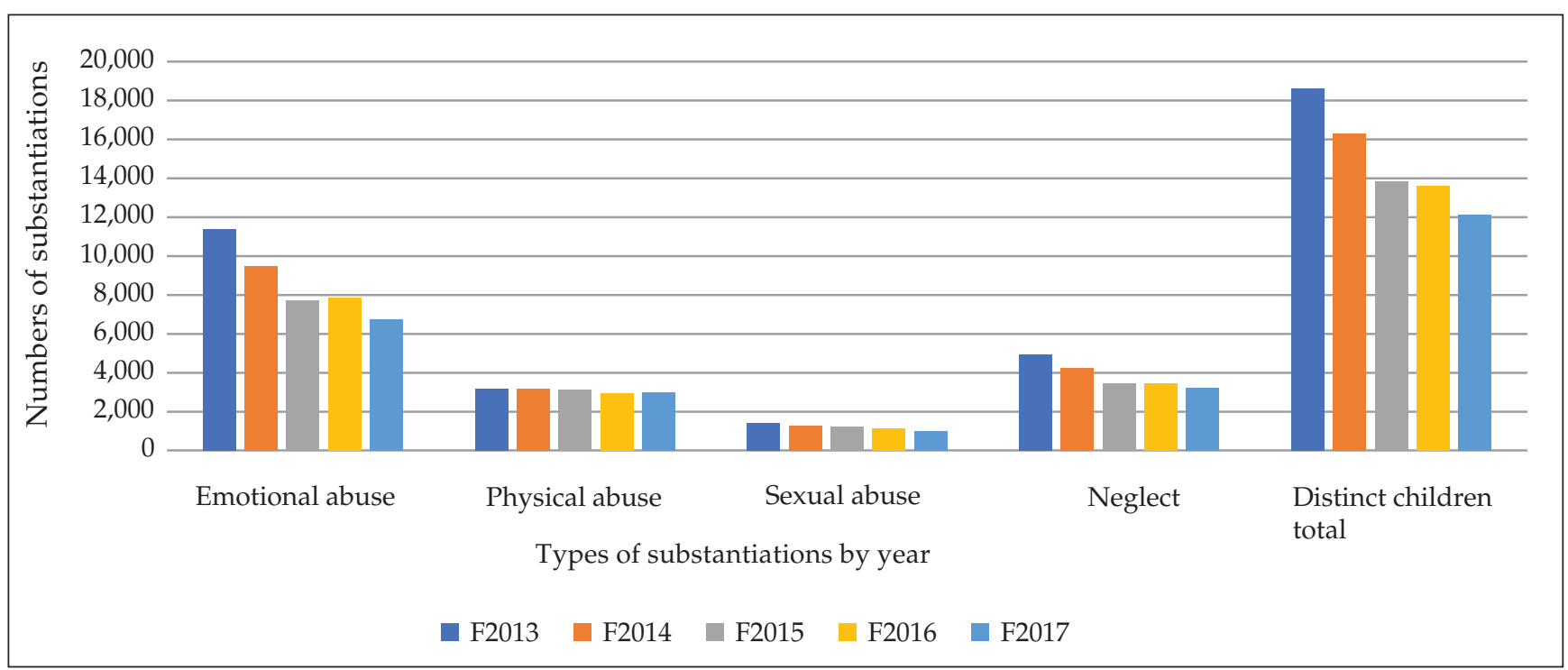

Figure 2. Child abuse substantiations in Aotearoa NZ, 2013-2017.

There are no absolute measures of child abuse, as it is underreported across the population (Daro, 2009). However, some fairly objective measures of child physical abuse also show reductions. The rates of hospitalisation for child maltreatment (from the National Minimum dataset and summarised by Duncanson et al., 2018) have reduced over time, from 50 per 100,000 in 1991, to 20 per 100, 000 in 1995, where it remained reasonably steady until 2007. From 2007 until 2017 however, it has continued to decline, from 20 to 12 per 100,000 in 2017, a reduction of $40 \%$ (Duncanson et al., 2018). 


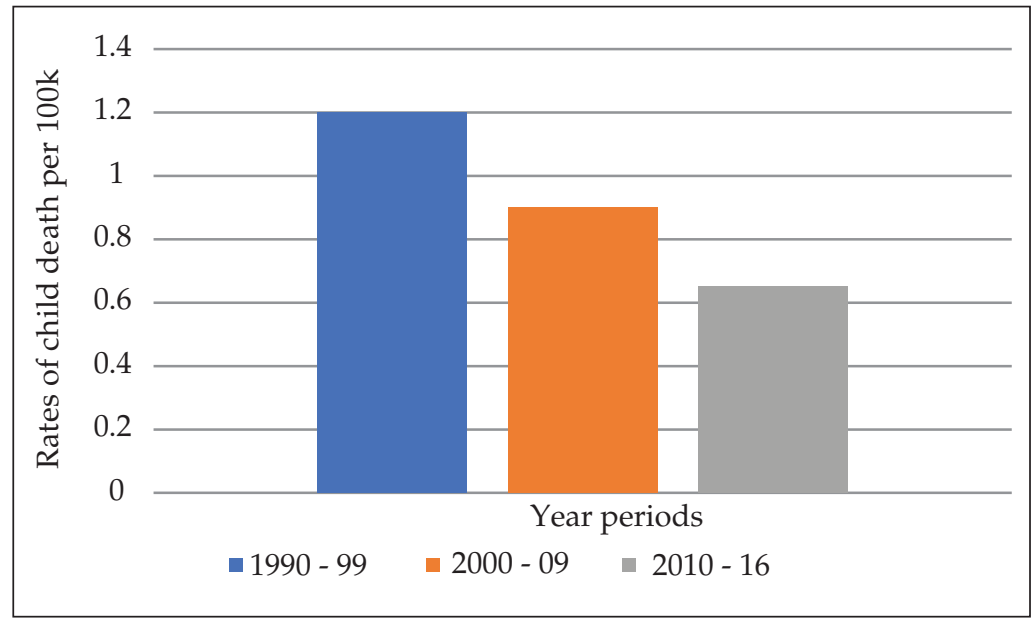

Figure 3. Rate of child deaths by maltreatment 1990-2016 per 100,000.

Reported use of "physical punishment, such as smacking" by parents in the previous four weeks in the New Zealand Health Survey has halved from $10 \%$ in $2006 / 7$ to 5\% in 2016/7 (Duncanson et al., 2018). So, despite substantiated physical abuse staying steady in OT data, hospital admissions are dropping.

Child deaths are difficult to deduce patterns from due to small numbers and volatile changes. However, despite Aotearoa often stated as having a high rate of child death, this also may be reducing slowly.
By grouping and averaging the rates reported in the Child Poverty Monitor by 10 -year periods, (based on Ministry of Health mortality data) and adding the rate of child deaths for 2016 to extend the range (the number supplied by the Ministry of Health in a personal comm, and rate calculated using the child ERP for 2016), the rate of child deaths appears to be reducing (although the very low rate for 2016 was a single year rate of .19 so may have depressed the last average unfairly).

\section{Children in care increasing}

Despite the reductions in reports of concern, substantiations, hospitalisations, reported physical abuse and possibly deaths, the number of children in care has steadily risen since 2013. As can be seen in Table 1, this increase represents an overall increase in raw numbers, as well as a proportion of all children. Table 1 shows that children in out-of-home care have increased by $23 \%$, an increase in the rate per 10,000 children of 19\% (using the ERP child denominator). The biggest increase is in babies and children under the age of 10: children aged 5-9 (31\%), then aged $2-4(17 \%)$ and $0-1(16 \%)$. This increase is often explained as the result of the increase in age-of-care leaving, but the data by age shows that the numbers of young people

Table 1. Distinct Children in Out-of-home Placements (Point in time-end of June)*

\begin{tabular}{|c|c|c|c|c|c|c|}
\hline Placement Type & 2013 & 2014 & 2015 & 2016 & 2017 & $\%$ change 2013-2017 \\
\hline Non Family / Whānau & 1,298 & 1,269 & 1,182 & 1,281 & 1,368 & +5 \\
\hline Family / Whānau & 1,698 & 1,999 & 2,193 & 2,303 & 2,515 & +48 \\
\hline $\begin{array}{l}\text { Child and Family Support } \\
\text { Services }\end{array}$ & 521 & 536 & 502 & 507 & 541 & +4 \\
\hline CYF Family Home & 103 & 114 & 133 & 154 & 116 & +11 \\
\hline Residential Placement & 47 & 34 & 29 & 35 & 29 & -38 \\
\hline $\begin{array}{l}\text { Other Supported } \\
\text { Accommodation }\end{array}$ & 177 & 177 & 124 & 114 & 147 & -17 \\
\hline $\begin{array}{l}\text { Distinct children and young } \\
\text { people }\end{array}$ & 3,844 & 4,129 & 4,163 & 4,394 & 4,716 & +23 \\
\hline Total children ERP & $1,031,900$ & $1,034,720$ & $1,041,590$ & $1,051,140$ & $1,059,800$ & \\
\hline Rate & .0037 & & & & .0044 & +19 \\
\hline
\end{tabular}

*Does not include those in the custody of the CE, but placed at home or remaining at home. 
in care aged 14 and over have instead reduced slowly, from 1,119 in 2013, to 1,104 in 2017. Even before the increase to the age-of-care leaving (April 1 2017), care numbers and rates of younger children were showing marked increases. This age spread may have changed since that time as the age rise takes effect.

\section{Entries and exits from care}

Drilling down into the overall growth in numbers of children in care, another trend of interest is the entries to care and exits from care shown in Table 2. Although overall the numbers of children in care have increased, entries to care have reduced 2013-2018 by $10 \%$. Exits have reduced much more sharply, by $34 \%$. Once they are placed in care, they are more likely to stay for longer, pushing up overall numbers in care at any one time.

\section{Kinship care increasing}

Who is caring for children while in care? Table 1 shows how this trend is being responded to. The biggest increase in care type, with a $48 \%$ increase $2013-2017$, is in the use of family/whānau placements, while non-kin care placements increased by only $5 \%$, and residential placements reduced. However, due to the increase in numbers overall, this translates into a small increase of kinship care as a proportion of all care, from $44 \%$ to $53 \%$. This increased use of whānau care may be the reason for the reductions in children moving into "home for life", that is, permanent foster care with nonkin placements. This number has reduced since 2013, from 417 that year, to 331 in the 2017/18 year (Oranga Tamariki, 2018b).

\section{Māori disproportionality}

While the use of whānau care may be considered, in some ways, to offset the potential harms of an increase in care, in general disproportionality for Māori is continuing to rise. In the overall, all-age care numbers, Māori disproportionality has increased from 100 per 10,000 in 2012, to 132 per 10,000 in 2017.
Table 2. Entries and Exits from Oranga Tamariki care 2013-2018

\begin{tabular}{|l|r|r|}
\hline \multicolumn{1}{|c|}{ Financial year } & \multicolumn{2}{|c|}{ Entries } \\
\hline $2013-2014$ & 2118 & 1877 \\
\hline $2014-2015$ & 1753 & 1778 \\
\hline $2015-2016$ & 2076 & 1733 \\
\hline $2016-2017$ & 1996 & 1575 \\
\hline $2017-2018$ & 1915 & 1246 \\
\hline Reduction in $\mathrm{n}$ and \% & $-203=10 \%$ & $-631=34 \%$ \\
\hline
\end{tabular}

Māori over-representation continues to climb compared to children from other ethnic groups, and compared to the overall Māori child population. For example, Māori were $54.7 \%$ of children in care in June 2013 , but $61.2 \%$ of children in care in 2017, despite the estimated resident Māori under-17 population remaining steady over that time period at around $25 \%$. The Pākeha proportion of children in care over the same time period reduced from $33.2 \%$ to $26 \%$. Pacific children numbers remain fairly stable in both Pacific statistics reported here, and in multiple measure proportions (reported later). For example, for children in care, Pacific children were $8 \%$ of those in care in 2013, and 7.3\% of those in care in 2017. This proportion is below the Pacific child population of $13.4 \%$ in 2013 (Statistics New Zealand, 2019). What is remarkable, and probably a reflection of recording practices, is that, despite the very high rates of multiple ethnicity in the general child population, the rates of children in care with reported multiple ethnicity is only $1.4 \%$. These ethnicity measures need more scrutiny as, for example, if the numbers of multiple ethnicity children are being prioritised in the OT data, then this will decrease all non-Māori groups (Keddell, 2017c; Kukutai, 2011). Prioritisation refers to the practice of categorising people who give multiple ethnic identities in a preference hierarchy of: Māori, Pacific, Asian, MELAA, and Pakeha.

Another lens of disproportionality is to calculate the Māori rate compared to the 


\section{ORIGINAL ARTICLE}

\section{QUANTITATIVE RESEARCH}

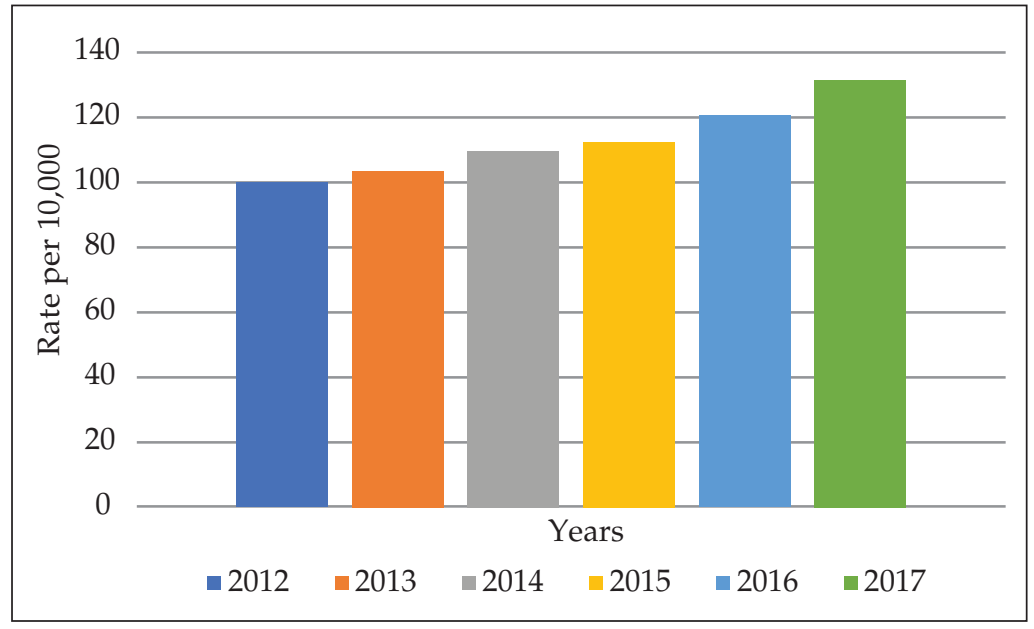

Figure 4. Rate of Māori children in care per 10,000, 2012-2017.

Māori child population. Figure 4 shows the rates of Māori children in care as a rate of all Māori children in the estimated population. As can be seen, this rate is also increasing, from 100/10,000 to 131 between 2012 and 2017.

\section{Babies}

A particular concern is in relation to the rates of newborn removals. Prevention services are valuable for all families, but the earliest of intervention is needed with families at the time of birth. This need is especially evident, as the removals of babies within three months of birth have increased since 2015, from 211 to 281 , an increase of $33 \%$, or a rate per 10,000 births from 35 to 46 (2015-2018) (see Table 3). Before, this, numbers were fairly stable between 2010 (210 babies removed) and 2015 (211 babies removed) (see Figure 5). This increase coincides with the policy reform began in 2015 with the modernising panel report and birth of Oranga Tamariki, although external factors on the demand side, as examined in the discussion section, cannot be ruled out as also contributing. The increase does not appear to be directly caused by the "subsequent children" legislative changes, as only one baby was removed in 2017, and four in 2018, were removed under this provision (the total is @280). It is possible, however, that the spirit, if not the letter, of the law has affected practice logics.

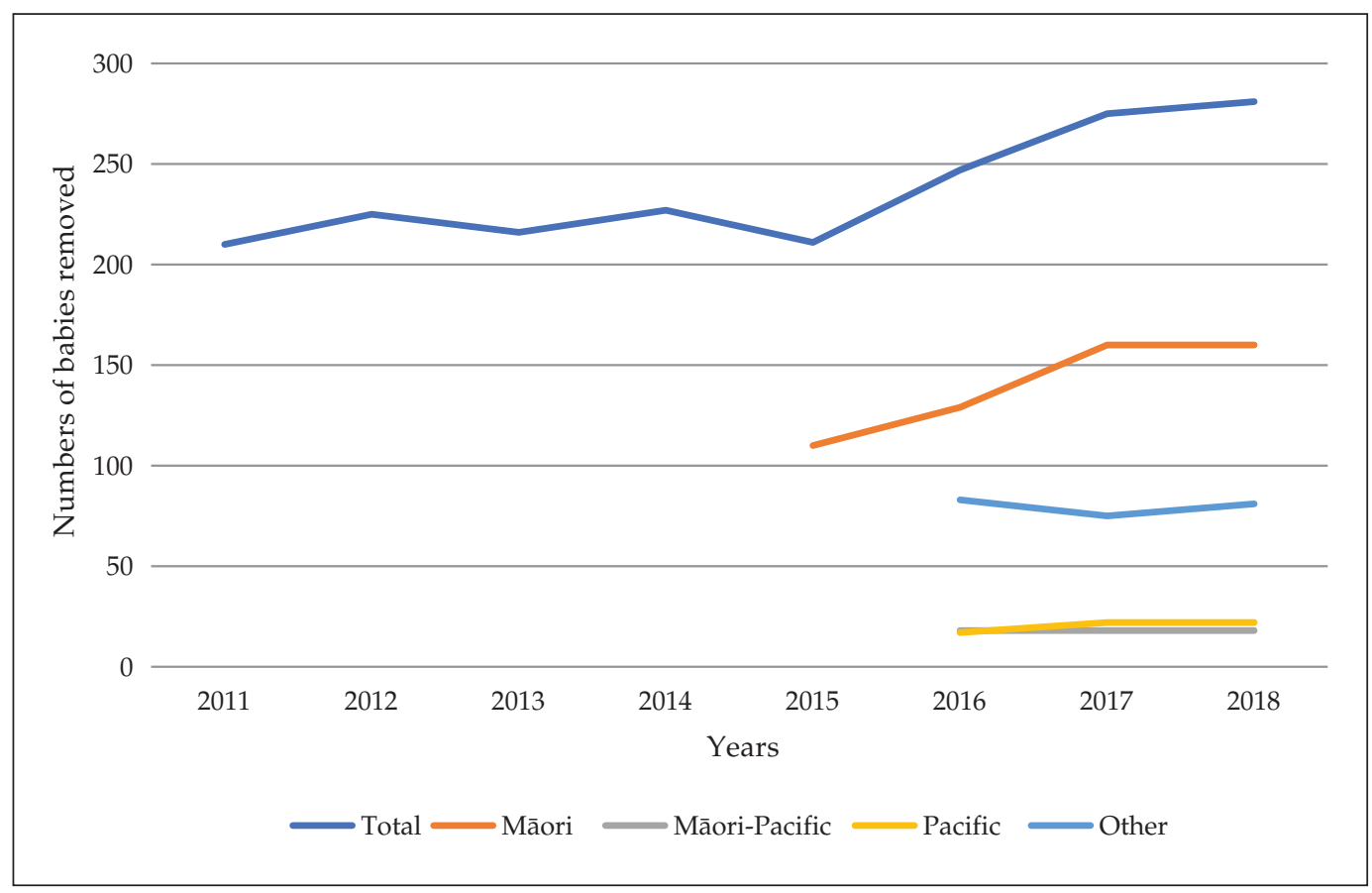

Figure 5. Babies removed within three months of birth 2011-2018. 
The ongoing disproportionate representation of Māori in this group is marked, with a rate of newborn removal in 2018 of 103 per 10,000 births, compared to the non-Māori rate of 24 per 10,000 births (Figure 6). Examining these figures further, it can be seen that the non-Māori rate has been stable since 2015 at 23-24 per 10,000 births, suggesting that the brunt of the increase is borne by Māori communities, as can be seen in Figures 5 and 6. Pacific babies also show a small increase for those categorised as "sole Pacific", but Māori-Pacific numbers are stable, though there are very small numbers in both categories, so this may not show any trend (see Table 3).

For comparison, there was an outcry in England recently due to the rate of baby removals over the last 10 years doubling to 35 per 10,000 births-but our overall rate is much higher at 46, and for Māori, now very high at 103/10,000 (Broadhurst et al., 2018). This is concerning, especially considering
Table 3. Babies Removed within Three Months of Birth 2015-2018, by Ethnicity

\begin{tabular}{|c|c|c|c|c|c|c|c|c|c|c|}
\hline & \multicolumn{2}{|c|}{2015 * } & \multicolumn{2}{|c|}{2016} & \multicolumn{2}{|c|}{2017} & \multicolumn{2}{|l|}{2018} & \multicolumn{2}{|c|}{$\%$ change $e^{* *}$} \\
\hline & $\mathrm{N}$ & $\%$ & $\mathrm{~N}$ & $\%$ & $\mathrm{~N}$ & $\%$ & $\mathrm{~N}$ & $\%$ & $\mathrm{~N}$ & $\%$ \\
\hline Māori only & 110 & 52 & 129 & 52 & 160 & 58 & 160 & 57 & 50 & +45 \\
\hline Māori-Pacific & & & 18 & 7 & 18 & 7 & 19 & 7 & 1 & +6 \\
\hline Total Māori & & & 147 & 60 & 178 & 65 & 179 & 64 & 32 & +22 \\
\hline Pacific only & & & 17 & 7 & 22 & 8 & 21 & 8 & 4 & +23 \\
\hline Total Pacific & & & 35 & 14 & 40 & 15 & 40 & 14 & 5 & +14 \\
\hline $\begin{array}{l}\text { Non-Māori/ } \\
\text { Non-Pacific }\end{array}$ & (nor & $\begin{array}{l}101 \\
\text { Māori } \\
\text { only) }\end{array}$ & 83 & 34 & 75 & 27 & 81 & 29 & 21 & -20 \\
\hline Total & & 211 & & 247 & & 275 & & 281 & 70 & +33 \\
\hline
\end{tabular}

* Due to numbers for this coming from different information act requests, there is no ethnicity breakdown beyond Māori/non-Māori for 2015.

** Percentage changes are from 2015 for Māori and non-Māori, and from 20162018 for all other categories.

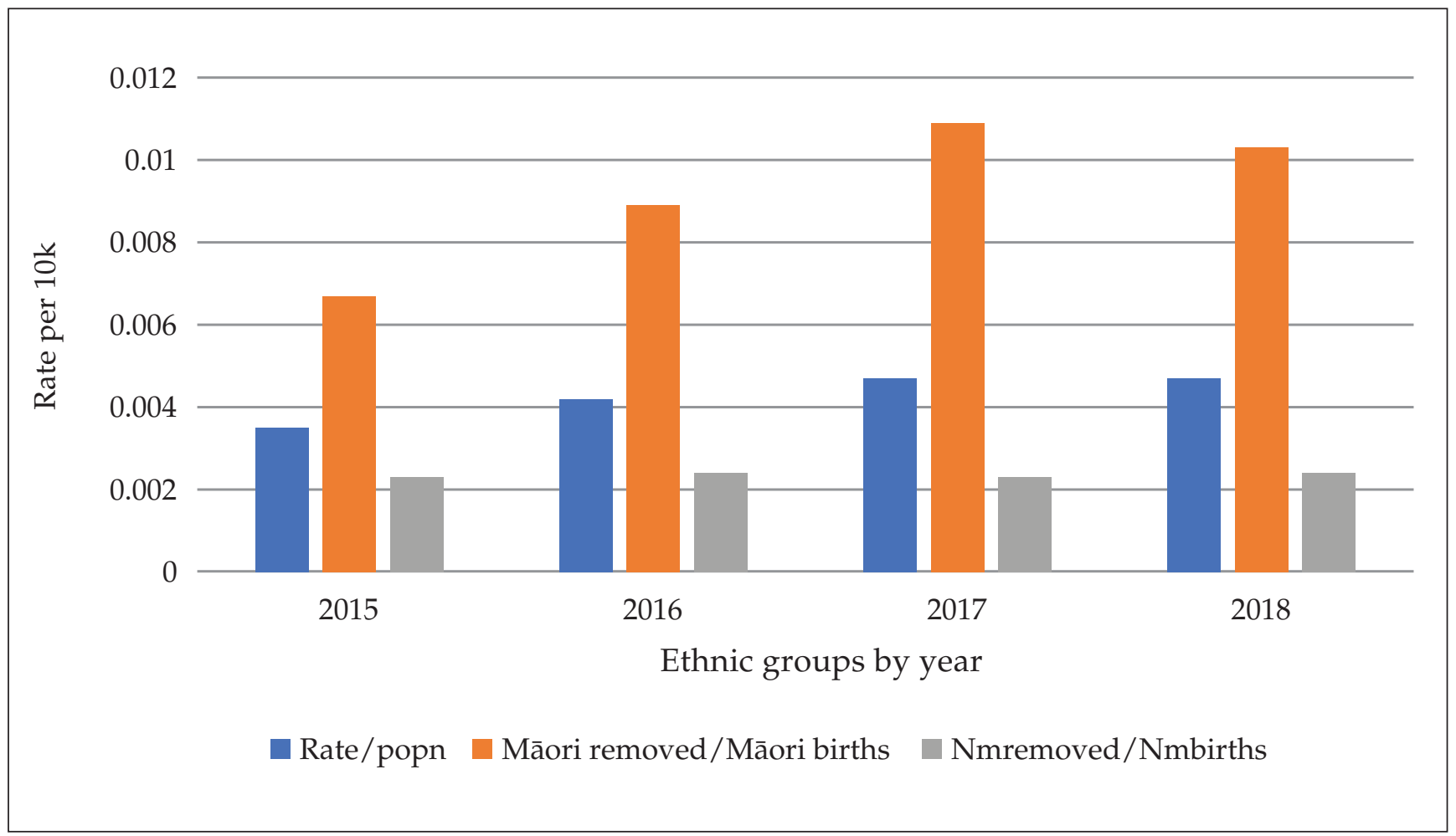

Figure 6. Māori and non-Māori rates per 10,000 of babies removed within three months of birth 2015-2018. 


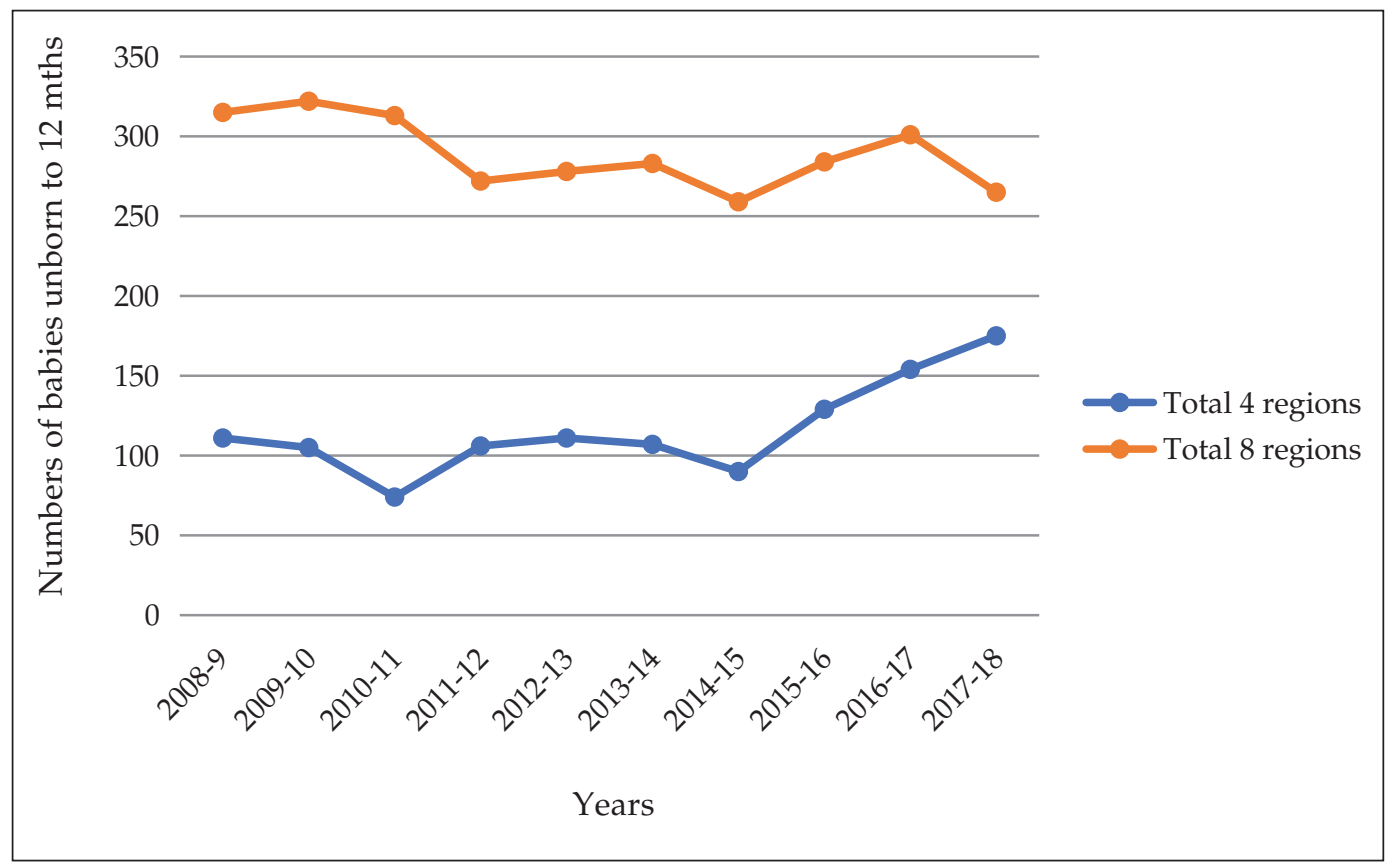

Figure 7. Regional comparison of babies removed 2008/9-2017/18.

*4 regions are Waikato, Te Tai Tokerau, Wellington and East Coast

*8 regions are North and West Auckland, Central Auckland, South Auckland, Bay of Plenty, TaranakiManawatu, Upper South, Canterbury, Lower South.

the many inclusions in the Oranga Tamariki Act amendments purportedly to address Māori concerns and the long history of inequities for Māori in the child protection system.

\section{Regional differences}

There are significant regional differences in rates of baby removal, as well as changes in how babies enter care and at what age (from Oranga Tamariki Data, 2019).

Dissecting by region in Figure 7 shows that the entire increase $09-18$ is accounted for by four regions: Tai Tokerau, Wellington, East Coast and Waikato (Oranga Tamariki regions). Comparing these four regions to the remaining eight from 2008/9-17/18 shows that these "top four" have increased from 111 to 175 babies removed, while the other eight have actually reduced from 315 to 265 . These need further calculation as rates, but suggest a need for further exploration.
Another pattern is that there has been a large increase in orders made for unborn children, compared to babies aged 30 days to one year old. Orders on unborn babies increased from 34 in 2008-2009, to 112 in 2017/2018, while babies aged 0-7 days reduced slightly, 8-30 days increased slightly, and age 30 days to one year old decreased (Oranga Tamariki, 2019). The level of mandated removals have also increased. Removals by order rather than agreement or arrangement have increased. Removal by s78 order or "urgency" has increased from 258 in $2008 / 2009$, to 380 in 2017/2018, while babies entering care by arrangement or agreement declined from 168 to just 60 . This means that, in $2008 / 2009$, removal by agreement made up $39 \%$ of babies removed-now it is just $14 \%$, while removals by order as a proportion of removals increased from $60 \%$ to $86 \%$. Interestingly, this pattern holds for children of all ages: care by agreement for all children has reduced from $47 \%$ to $24 \%$ of children entering care 08/09-17/18 (Oranga 
Tamariki, 2019). Overall, these patterns show that the increase in babies entering care are entirely accounted for by an increase in removals of Māori babies in four regions, with an increasing proportion removed by legal order as opposed to by agreement, and of those "unborn" as opposed to older babies.

\section{Discussion}

Descriptive data can give broad insights into trends in the child protection system, pointing to emerging issues and providing directions for more nuanced research questions and methods. These data in the Aotearoa New Zealand context show there is an increase in time spent in care for some groups (most notably Māori and young children including babies) alongside generally heightened criteria for entry to the care system, against a background of reduction in objective measures of physical abuse harm. Objective measures of child physical abuse, self-reported use of physical punishment and child protection data on reports and substantiations are reducing, as are entries to the care system. Yet once children are in care, they are remaining for longer, but are increasingly likely to be placed with whānau caregivers. Due to children remaining in care for longer, the overall numbers and rates of children in care are increasing.

Māori disproportionality (compared to the general Māori child population) and disparities (compared to other ethnic groups) are both increasing in the care population showing the ongoing reproduction and worsening of historic disparities (Keddell \& Hyslop, 2019). The largest increases by age 2013-2017 are in children under aged 5-9 at 31\%, but the later data on newborns show an even greater increase 2015-2018 of 33\%. Examining the baby increase further shows that this increase is racialised, with the total increase accounted for by an increase in Māori babies removed while other group rates remain stable. But ethnic disparity is only part of the picture, as the baby increase is also accounted for by only four out of the total 12 regions, while the other eight regions have remained stable or reduced (although rates by region are not calculated).

There has also been in increase in orders on unborn babies compared with orders on older babies, and an increase in the use of legal orders as opposed to care by agreement. Legal orders are increasingly occurring during the antenatal period, rather than after babies are born. This gives women and other family members less opportunity to show if they are able to parent or not, highlighting increasing risk aversion by the statutory agency (Mornington \& Guyard-Nedelec, 2019). Removals are also more coercive than previously, with less use of care by agreement, showing similar patterns to Parton's (2016) observation that trends in many Anglophone countries show an "authoritarian turn" in child protection that affects certain sectors of the populationthose living in poverty. Baby removal patterns are therefore reinforcing racialised inequalities, but also have regional patterns, occurring in regions with large Māori populations, large rural areas and high deprivation.

I now turn to discuss these patterns with reference to the policy context, drawing on an inequalities theoretical perspective and the context of policy reform. Increases in care can be understood as factors affecting the demand side-those factors increasing demand for child protection services; factors on the supply side-those factors relating to how OT responds to that demand; and factors affecting the interface between the two (Bywaters et al., 2015).

On the demand side, some of the increase in children in care may be grounded in the realities of increasing pressure on families themselves, with ongoing poverty/housing issues, poor access to relevant adult services, and not enough tiered support services 
available in the community (from general family support services, to tertiary "edge of care" preventive services, to support services for reunification) (Bywaters, Brady et al., 2018). These demand side factors have not been addressed comprehensively in policy, particularly as the Vulnerable Children's and modernising reform process focussed on an "individualistic framing of the causes of abuse [that] downplays key evidence about the relationship between child abuse and neglect and the broader social and economic context" (Keddell, 2017a, p. 9). This led to a stated focus on early intervention, but limited resources to operationalise it outside the statutory system, that is, to reduce poverty or support the NGO and Iwi community services tasked with the provision of preventive services, estimated to be 630 million dollars short each year (Jenkins, 2019). Especially for pregnant women, there may be an unmet need for preventive or intensive family preservation services. This may also affect Māori particularly, as Māori are more likely to be living in high deprivation areas, and services may not be sufficiently well matched to cultural and economic needs (Raissian \& Bullinger, 2017).

Institutionalised ethnic and socioeconomic biases can affect processes on both the demand and supply side of services (Cram, Gulliver, Ota, \& Wilson, 2015). Exposure bias can operate on the demand side, where populations in high deprivation areas (and within that group, Māori and Pacific communities), are more likely to be exposed to referrers. On the supply side, Māori are likely to be perceived as more risky than non-Māori families by practitioners, contributing to over-representation (Keddell \& Hyslop, 2019). This may be particularly affecting the rates of baby removal as three of the four regions showing increases have high Māori populations and large areas of high deprivation, yet some areas with similar demographic features-such as Auckland and Taranaki-do not show this pattern. The increasing inclusion of domestic violence as a risk factor may also ratchet more Māori whānau into the child protection system. Māori women are more likely to be victims of domestic violence, which combined with the prevailing "failure to protect" narrative can result in the removal of children, rather than the protection of both women and children (Humphreys, Healey, \& Mandel, 2018). More research is needed to understand this trend.

While there are more Māori children in care, there is a commitment to kinship care. Whether this reflects an ongoing ideological commitment to kin care, the large proportion of Māori children coming into care who now have even stronger legislative imperatives to consider kin placements for, or a practical response to the lack of alternative foster placement requires research to ascertain.

At the point of interface between OT and the rest of the child welfare system, there are also factors affecting the changing patterns of contact. Substantiations have dropped markedly, accepted reports of concern have dropped, and entries to care have reduced. Once children get through this higher threshold, whether they are more likely to enter care is not known, but once they are in care, they are likely to stay in care for longer. At this interface, it appears entry to OT has been tightened, reflecting an effort to accept only the most serious cases of abuse, while others are directed back to community services (Office of the Chief Social Worker, 2014). Once they are accepted, however, it appears that the focus is on investigation and a more muscular, interventionist response, as has been reported elsewhere in the world (Parton, 2016). The reduction of prevention support services, combined with a more authoritarian response to families increases intervention in family life, and this appears most marked in relation to babies (Parton, 2016). The increasing use of s78 interim care orders, as opposed to family whānau agreements, as well as the increase in orders on unborn babies, as opposed to older children, also reflects this change. The "early intervention into 
permanent care arrangements" emphasised in the modernising reforms appears to both increase baby removal and reduce efforts for reunification, as well as reduce the support service provision required to facilitate and support reunification. Without connections made to broader inequalities, there may also be less emphasis on the social needs of families for reunification to occur (such as adequate housing, income and adult therapeutic services).

As Hood et al. (2019) note, demand for child protection services does not simply reflect deprivation or community need, instead the regulatory functions of the child protection system "...through which agencies help to enforce socially acceptable standards of parental care and other aspects of family life, are sensitive to the attitudes and perceptions of many stakeholders, including service users, practitioners, managers, politicians, the media and the general public" (Hood et al., 2019, p. 1). Because of this, the ways demand is managed or responded to on the supply side can be shaped by multiple stakeholders. In this instance, supply may be influenced by the rhetoric of the policy reforms in the context of a critical public and political desires to be seen to be sorting out child protection via the get-tough approaches of the VCA reforms, and the efficiency and future outcomes logics of social investment in the modernising reforms. On the supply side, (internal OT policy and practice), the "safe and loving homes at the earliest possible opportunity" (repeated multiple times in the expert advisory panel report), was a powerful policy discourse that dichotomised families with foster care, and encouraged early removal as a solution that would solve later poor outcomes (Keddell, 2018). The social investment concepts of getting in early to prevent later costs, when equated with removal, assumed that removal leads to better outcomes over time for the child, when that conclusion is deeply contested (Doyle, 2011; Office of the Children's Commissioner, 2016). The trauma-informed/child-centred practice approaches encouraged in practice guidelines can obscure social understandings of family difficulties and diminish wholeof-family responses (Beddoe \& Joy, 2017; Hyslop, 2017).

A heightened emphasis on the trauma of the child may also contribute to extended stays in care. Keddell (2017b) found practitioners who were more risk-averse in decisionmaking also used more trauma-related concepts to explain family problems that focussed on poor future outcomes for the child, while those who focussed on present needs were less risk-averse. With the rapid uptake of trauma as a key concept, this may also have an effect if used in a deterministic manner, where future child effects are assumed certainties, and parental trauma is viewed as a source of risk rather than need (Beddoe \& Joy, 2017; Gillies, Edwards, \& Horsley, 2017). Instead of support, especially when combined with powerful ideas from neuroscience, this can be used instead to justify "gendered, raced and social inequalities, positioning poor mothers as architects of their children's deprivation" (Edwards, Gillies, \& Horsley, 2015, p. 167). All these concepts can lead to a system focus on the child alone at the expense of family support, reduce a view of children as intrinsically connected to family, whānau and community, and heighten perceptions of risk, while reducing a focus on family supports or rights-despite the reductions in serious physical abuse in the community (Hyslop, 2017).

A contributing factor to the pattern of fewer children entering care, but staying longer, may be the amount of supplied service (as opposed to its conceptual basis). That is, as the system became more focussed in the highest risk cases (due to the workload review) this allowed more intervention with the cases that were accepted. Accepting fewer cases frees up resources to enable greater intervention with those accepted, especially in the context of less focus on reunification or available family support services (Bywaters, Brady et al., 2018; McLaughlin \& Jonson-Reid, 2017). 
There are ongoing ambiguities, possibilities and counter-factual interpretations. Multiple legislative changes occurred throughout the Vulnerable Children and modernising reforms, reflecting the conceptual directions described above, but the child-focussed nature of them was bitterly contested by Māori. Reducing the emphasis on whakapapa and Māori whānau connections in the original draft was challenged by many Māori organisations and iwi. The resulting legislation therefore responded to both drivers: strengthening children's best interest and safety provisions, while also emphasising rights to whakapapa, by including the s7AA requirement to make decisions in partnership with whānau and hapū under the Treaty of Waitangi. It also set measurable reductions for Māori children in care. Thus far, as s7AA has only now (in mid-2019) been implemented, it may be that the earlier legislative changes have yet to be balanced out by the emphasis on retaining whakapapa ties and considering the Treaty obligations in legal decisions. Likewise, as mentioned, the intensive intervention services planned under the modernising reforms are currently under development. There is a Child Poverty Reduction Bill that may yet reduce poverty-related demand (though there is no sign of that yet-see St. John \& Cartwright, 2019). All of these developments provide the possibility of reducing care going forward.

Alternative explanations should also be considered. It could be that more children are in care because the system is better targeted towards the highest-risk cases, meaning that increased seriousness at intake equates to justified longer stays in care. The reduction in children leaving care could be related to the reduction in the use of the "home for life" policy, where foster parents' orders under the Oranga Tamariki Act were discharged in favour of orders under the Care of Children Act, effectively removing them from the data on children in the care of the CE of Oranga Tamariki. This increase could therefore be a data artefact rather than true change, as those children are still in reality, in foster care, quite apart from any change in the practices, policies or conditions that got them there. Alternative views on the ideological function of the child protection system also come into play when evaluating system change. A more protectionist-residualist political position postulates the correct role of the state is that of an investigate-remove structure for high-risk cases, while child welfare/ family service models emphasise the role of social protections and services as important preventive measures (Gilbert et al., 2011). Which assumptions are accepted, shapes the analysis of changes such as these. Finally, with little research on outcomes for babies or their family members, it is impossible to conclude that removal is either better or worse for specific babies and their whānau.

More research is needed to examine the relationships between these descriptive data trends and possible causes according to the inequalities and policy discourse concepts suggested. Particularly, establishing the cause of reductions of children leaving care, the criteria for entry, the increases for Māori compared to other groups, the increase in newborn removals and their regional, antenatal and more coercive nature, all require more research. The patterns themselves suggest marked changes in the interface between the state and family life. There is more intervention, particularly for young children, despite reducing harm, and this intensifies the profound inequities wrought by colonisation for Māori that are longstanding in our child protection system. While removal is not always avoidable, there is a general consensus that, where removal can be prevented, it should be, in support of both children and parent's rights to family life, and children's long-term outcomes (Broadhurst et al. 2018; Choate, 2015). Understanding how this web of influences can be untangled to understand the recent increases, in the context of reducing serious risk of harm, is important going forward. 


\section{References}

Bécares, L., Cormack, D., \& Harris, R. (2013). Ethnic density and area deprivation: Neighbourhood effects on Māori health and racial discrimination in Aotearoa/ New Zealand. Social Science \& Medicine, 88, 76-82. doi:http://dx.doi.org/10.1016/j.socscimed.2013.04.007

Beddoe, L., \& Joy, E. (2017). Questioning the uncritical acceptance of neuroscience in child and family policy and practice: A review of challenges to the current doxa Aotearoa New Zealand Social Work 29(1), 65 - 76. doi:10.11157/anzswj-vol29iss1id213

Broadhurst, K., Alrouh, B., Mason, C., Ward, H., Holmes, L., Ryan, M., \& Bowyer, S. (2018). Born into care: Newborn babies subject to care proceedings in England. London, UK: The Nuffield Family Justice Observatory.

Bywaters, P. (2015). Inequalities in child welfare: Towards a new policy, research and action agenda. British Journal of Social Work, 45(1), 6-23. doi:10.1093/bjsw/bct079

Bywaters, P., Brady, G., Bunting, L., Daniel, B. Featherstone, B., Jones, C., . . W Webb, C. (2018). Inequalities in english child protection practice under austerity: A universal challenge? Child \& Family Social Work, 23(1), 1365-2206. doi:10.1111/cfs.12383

Bywaters, P., Brady, G., Sparks, T., Bos, E., Bunting, L., Daniel, B., ... Scourfield, J. (2015). Exploring inequities in child welfare and child protection services: Explaining the "inverse intervention law". Children and Youth Services Review, 57, 98-105. doi:http://dx.doi. org/10.1016/j.childyouth.2015.07.017

Bywaters, P., Scourfield, J., Jones, C., Sparks, T., Elliott, M. Hooper, J., . . Daniel, B. (2018). Child welfare inequalities in the four nations of the UK. Journal of Social Work. doi:10.1177/1468017318793479

Choate, P. (2015). Termination of parental rights: A commentary on Ben-David. Journal of Family Social Work, 18(4), 243-252. doi:10.1080/10522158.2015. 1083393

Cram, F., Gulliver, P., Ota, R., \& Wilson, M. (2015). Understanding overrepresentation of indigenous children in child welfare data: An application of the Drake risk and bias models. Child Maltreatment, 20(3), 170-182. doi:10.1177/1077559515580392

Daro, D. (2009). The history of science and child abuse prevention: A reciprocal relationship. In K. Dodge \& D. Coleman (Eds.), Preventing child maltreatment: Community approaches (pp. 9-25). New York, NY: The Guilford Press.

Doyle, J. J. (2011). Causal effects of foster care: An instrumental-variables approach. Children and Youth Services Review, 35(7), 1143-1151.

Duncanson, M., Oben, G., Wicken, A., Richardson, G., Adams, J., \& Pierson, M. (2018). Child poverty monitor 2018: Technical report (national report). Dunedin, NZ: New Zealand Child and Youth Epidemiology Service.

Edwards, R., Gillies, V., \& Horsley, N. (2015). Brain science and early years policy: Hopeful ethos or "cruel optimism"? Critical Social Policy, 35(2), 167-187.

Featherstone, B., Gupta, A., Morris, K. M., \& Warner, J. (2016). Let's stop feeding the risk monster: Towards a social model of "child protection". Families, Relationships and Societies. doi:http://dx.doi.org/10.1332/20467431 6X14552878034622
Gilbert, N., Parton, N., \& Skivenes, M. (2011). Child protection systems: International trends and orientations. Oxford: Oxford University Press.

Gillies, V., Edwards, R., \& Horsley, N. (2017). Challenging the politics of early intervention. Bristol, UK: Policy Press.

Hood, R., Goldacre, A., Gorin, S., \& Bywaters, P. (2019). Screen, ration and churn: Demand management and the crisis in children's social care. The British Journal of Social Work. doi:10.1093/bjsw/bcz035

Humphreys, C., Healey, L., \& Mandel, D. (2018). Case reading as a practice and training intervention in domestic violence and child protection, Australian Social Work, 71(3), 277-291.

Hyslop, I. (2017). Child protection in New Zealand: A history of the future. The British Journal of Social Work, 47(6), 1800-1817. doi:10.1093/bjsw/bcx088

Jenkins, M. (2019). Social service system: The funding gap and how to bridge it. Wellington, NZ: Social Service Provider Association.

Keddell, E. (2017a). The Child Youth and Family review: A commentary on prevention. Auckland, NZ: The Policy Observatory, AUT. Retrieved from https://thepolicyobservatory.aut.ac.nz/

Keddell, E. (2017b). Comparing risk-averse and risk-friendly practitioners in child welfare decision-making: A mixed methods study. Journal of Social Work Practice, 31(4), 411-429.

Keddell, E. (2017c). Lives at the intersections: multiple ethnicities and child protection. In M. Webber \& Z. Rocha (Eds.), Tangata manarua: Mixed heritages, ethnic identity and biculturalism in Aotearoa/New Zealand (pp. 252-278). Oxon, UK: Routledge.

Keddell, E. (2018). The vulnerable child in neoliberal contexts: the construction of children in the Aotearoa New Zealand child protection reforms. Childhood, 25(1), 93-108.

Keddell, E., \& Davie, G. (2018). Inequalities and child protection system contact in Aotearoa New Zealand: Developing a conceptual framework and research agenda. Social Sciences, 7, 89-100.

Keddell, E., Davie, G., \& Barson, D. (2019). Child protection inequalities in Aotearoa New Zealand: Social gradient and the "inverse intervention law". Children and Youth Services Review. Online first at: https://doi.org/10.1016/j.childyouth.2019.06.018

Keddell, E., \& Hyslop, I. (2019). Ethnic inequalities in child welfare: The role of practitioner risk perceptions. Child \& Family Social Work, 1-12. Online first at: doi:10.1111/cfs. 12620

Kukutai, T. (2011). Building ethnic boundaries in New Zealand: Representations of Māori identity in the census. In Axelsson, P., \& Skold, P., (Eds.), Indigenous Peoples and Demography: The Complex Relation between Identity and Statistics, (pp.33- 54) New York, NY: Berghahn Books.

McLaughlin, M., \& Jonson-Reid, M. (2017). The relationship between child welfare financing, screening, and substantiation. Children and Youth Services Review, 82, 407-412. doi:https://doi.org/10.1016/j. childyouth.2017.10.013 
Ministry of Social Development. (2012). The white paper for vulnerable children (Vol. 1). Wellington, NZ: NZ Government. Retrieved from: https://www.orangatamariki.govt.nz/assets/Uploads/ white-paper-for-vulnerable-children-volume-1.pdf

Ministry of Social Development. (2015). Expert panel final report: Investing in New Zealand's children and their families. Wellington: Ministry of Social Development.

Ministry of Social Development. (2018). Key statistics and information for media. Retrieved from https://www.msd.govt.nz/about-msd-and-our-work/ publications-resources/statistics/cyf/index.html

Mornington, A.-D., \& Guyard-Nedelec, A. (2019). Is poverty eroding parental rights in Britain? The case of child protection in the early twenty-first century. In N. Brando \& G. Schweiger (Eds.), Philosophy and child poverty: Reflections on the ethics and politics of poor children and their families (pp. 341-361). Cham, Springer International Publishing.

New Zealand Government. (2019). Mental health inquiry. Retrieved from https://mentalhealth.inquiry.govt.nz/

Office of the Chief Social Worker. (2014). Workload and casework review: Qualitative review of social worker caseload, casework and workload management. Wellington, New Zealand: Child, Youth and Family.

Office of the Children's Commissioner. (2016). Children's commissioner says UN report must be taken seriously Retrieved from http://www.occ.org.nz/assets/Uploads/ FINALmediastatementUN.pdf

Oranga Tamariki. (2019). Babies and children entering Oranga Tamariki care. Retrieved from https://orangatamariki.govt.nz/assets/Uploads/OIAresponses/children-in-care/20190628-Babies-andchildren-entering-Oranga-Tamariki-care.pdf

Oranga Tamariki (2015a) Official Information Act request, Duff, September 21. Wellington, NZ: Oranga Tamariki.

Oranga Tamariki (2015b) Official Information Act request, Keddell, November 26. Wellington, NZ: Oranga Tamariki.

Oranga Tamariki (2018) Official Information Act request, Keddell, September 14. Wellington, NZ: Oranga Tamariki.

Parton, N. (2016). An "authoritarian neoliberal" approach to child welfare and protection? Aotearoa New Zealand Social Work, 28(2), 7-8.

Raissian, K. M., \& Bullinger, L. R. (2017). Money matters: Does the minimum wage affect child maltreatment rates? Children and Youth Services Review, 72, 60-70. doi:http://dx.doi.org/10.1016/j.childyouth.2016.09.033

Simpson, J., Duncanson, M., Oben, G., Wicken, A., \& Gallagher, S. (2016). Child poverty monitor: Technical report 2016 (national report). Dunedin, New Zealand: Child and Youth Epidemiology Service.

Statistics New Zealand. (2019). National Pacific projections. Wellington, New Zealand: Author. Retrieved from http://archive.stats.govt.nz/browse_for_stats/population/ estimates_and_projections/projections-overview/natpacific-proj.aspx

St. John, S., \& Cartwright, J. (2019, May 1). Get our children out of poverty. Tui Motu Magazine, 10-11. 